\title{
A Cross-sectional Study of Prevalence and Correlates of Tobacco Use in Three Districts of Punjab, India
}

\author{
${ }^{1}$ Garima Bhatt, ${ }^{2}$ Sonu Goel, ${ }^{3}$ Suman Mor, ${ }^{4}$ Rakesh Gupta
}

\begin{abstract}
Background and objectives: Tobacco use leads to over 7 million deaths each year worldwide and is expected to rise to over 8 million by 2030. The aim of the present study was to assess the prevalence of current tobacco use in the smoked and smokeless form in Punjab, India.
\end{abstract}

Methodology: This cross-sectional study was conducted from December 2015 till March 2016. A three-stage sampling technique was used for collecting data from three randomly selected districts representing three major regions of Punjab, India. A sample size of 510 individuals was divided equally into urban and rural area with proportionate sampling on basis of subsets of age groups and gender. The questionnaire based on tobacco questions for the survey (TQS), a subset of key questions from the global adult tobacco survey (GATS) was used.

Results: Overall, the prevalence of current tobacco use was $11.5 \%$. The smoked form was more prevalent (15.2\%) as compared to smokeless $(7.8 \%)$ form. The odds for smoked tobacco users are 4 times more in age group of 45 years and above (OR $4.9,95 \% \mathrm{Cl} 1.4,16.8)$. In addition, an antagonistic relationship between education and use of smoked tobacco was observed as the odds ratio decreased with increasing level of education (OR 0.83-0.13, C.I. 0.23-2.97, 0.02-0.74).

Conclusion: Tobacco use was low in Punjab, India especially in females as compared to other states of the country. Despite of low overall prevalence of tobacco use, it is higher among low socio economic underprivileged groups and people with low literacy levels. The focus of government should be on these groups and address the need for active tobacco cessation facilities in the state.

Keywords: Cigarette and Other Tobacco Products Act, Global adult tobacco survey, India, Smoked tobacco, Smokeless tobacco.

How to cite this article: Bhatt G, Goel S, Mor S, Gupta R. A Cross-sectional Study of Prevalence and Correlates of Tobacco Use in Three Districts of Punjab, India. J Postgrad Med Edu Res 2019;53(1):1-6.

Source of Support: Nil

Conflict of Interest: None

${ }^{1} \mathrm{PhD}$ Scholar, ${ }^{2}$ Additional Professor, ${ }^{3}$ Coordinator, ${ }^{4}$ Chief Chemical Examiner

${ }^{1,2}$ School of Public Health, Postgraduate Institute of Medical Education and Research, Chandigarh, India

${ }^{3}$ Centre for Public Health, Panjab University, Chandigarh, India

${ }^{4}$ Department of Health and Family Welfare, Government of Punjab, Punjab, India

Corresponding Author: Sonu Goel, Additional Professor, School of Public Health, Postgraduate Institute of Medical Education and Research, Chandigarh, India, e-mail: sonugoel007@yahoo.co.in

\section{BACKGROUND}

Tobacco use leads to over 7 million deaths each year worldwide and is expected to rise to over 8 million by 2030. In the 20th century, it had taken a toll of around 100 million with a projection of nearly one billion by the 21st century. ${ }^{2}$ Global Burden of Disease Study 2013, states that the Disability Adjusted Life Years (DALYs) attributable to tobacco smoking increased from 115.9 million to 134.2 million DALYs from 1990-2013. ${ }^{3}$ The estimated number of tobacco users in India is 274.9 million, of which 163.7 million use only smokeless tobacco, 68.9 million are only smokers, and 42.3 million use both smoked and smokeless tobacco. ${ }^{1}$

World Health Organization (WHO) identifies tobacco as one of the important risk factors for non-communicable diseases (NCDs) and a major cause of premature death. ${ }^{4}$ More than 16 million people already have at least one disease from smoking which is preventable. ${ }^{5}$ Smokers are more likely than nonsmokers to develop heart disease, stroke, and lung cancer. ${ }^{6}$ Smoking is estimated to increase the risk for coronary heart disease by $2-4$ times, ${ }^{6}$ for stroke by 2-4 times, 6 men developing lung cancer among men by 25 times $^{6}$ and among women by 25.7 times. ${ }^{6}$.

In response to the global tobacco epidemic, WHO developed the Framework Convention on Tobacco Control (FCTC), an all-powerful global instrument to counter the menace of tobacco which contains binding provisions on its member countries. It asserts focus on both demand reduction strategies and supply side issues, including regulation of trade and commerce. ${ }^{7}$ The government of India enacted 'Cigarettes and Other Tobacco Products (Prohibition of Advertisement and Regulation of Trade and Commerce, Production, Supply and Distribution) Act, 2003 (COTPA) and Smoke Act Rules (2008) to prohibit the consumption of cigarettes and other tobacco products. ${ }^{8}$ The State of Punjab in India has been a predecessor in its tobacco control efforts complying by the rules and regulations of the COTPA Act, 2003. Since 2010, Punjab has taken various measures and issued notifications for effective implementation of Tobacco Control Act which included authorization of competent persons to act against any person who violates the Act, constitution of State Level and District Level Monitoring Committees to monitor the implementation of the Act, involvement of stakeholders from different departments , prohibition 
of manufacture, storage, distribution or sale of chewable tobacco products including processed/flavored/scented chewing tobacco banning loose cigarettes and e-cigarettes in the entire state which led to declaration of Punjab as first large 'tobacco smoke free' state of India in 2015. 9 The objective of the present study was to assess the prevalence of current tobacco use in Punjab, India.

\section{METHODOLOGY}

\section{Study Settings}

The state of Punjab is situated in northwest India with a total area of 50,362 square kilometers and population of $2,77,04,236$. The state has twenty-two districts each under the administrative control of a District Collector. The rural area of a district is subdivided into tehsils $(\mathrm{n}=79)$, tehsil into blocks $(\mathrm{n}=143)$ and block into revenue villages $(n=12,278)$. The urban area comprises Zila parishads ( $n=22)$, municipal committees $(n=136)$ and towns $(n=143)$. Rural area constitutes approximately $70 \%$ of the total population of a district. The study was conducted in three randomly selected districts of Punjab namely, Hoshiarpur, Amritsar, and Bathinda. Hoshiarpur district is located in Doaba region of Punjab with 10 blocks, and 9 municipal councils. The Bathinda district is in Malwa region of the state with 9 blocks and 20 municipal councils. Amritsar district is located in the Majha region of Punjab with 9 blocks and 6 municipal councils. ${ }^{10}$

\section{Study Design and Study Population}

A cross-sectional descriptive study was conducted amongst the adult population aged 15 years and above in three randomly selected districts of Punjab, India from 1st December 2015-31st March 2016.

\section{Sample Size and Sampling Design}

A sample size of 510 respondents aged 15 years and above was obtained based on the prevalence of tobacco users in the state of Punjab as $12 \%(\mathrm{p})^{1}, 3 \%$ absolute error, $10 \%$ nonresponse rate. This sample was equally distributed in these selected districts with each district allocation of 170 households. The sample of a district $(n=170)$ was equi proportionately distributed to rural and urban areas. The sample size was further divided proportionately on the basis of the population into different subsets of age group and gender.

For the selection of households, three-stage stratified sampling design was adopted. In an urban area, the primary sampling units were municipal councils, secondary sampling units were city wards, and the tertiary sampling units were households. In a rural area, the blocks were the primary sampling units, villages were the secondary sampling units, and households were the tertiary sampling units. $30 \%$ of blocks from all the blocks of selected districts $(\mathrm{N}=28 ; \mathrm{n}=9$ ) and similarly, 30\% of municipal councils from all municipal councils $(\mathrm{N}=35$; $\mathrm{n}=10$ ) of chosen districts were selected randomly. From each block, five villages were selected randomly. Using systematic sampling half of the selected households were randomly assigned to be "male" and half were assigned as "female". From the male designated households, only males were interviewed, and those designated as female households only females were interviewed. Using KISH selection grid method one individual was picked from each selected household. The KISH selection grid method requires enlistment of all household members by sex and by age from eldest to youngest. Then, using a random number table, a person is chosen from the given household and is interviewed. ${ }^{11}$

\section{Data Collection and Analysis}

Data collection was done using a standard questionnaire based on tobacco questions for surveys (TQS), a subset of key questions from the GATS. ${ }^{12}$ The content of the questionnaire contained demographic information of respondents, and tobacco use behaviour in smoked and smokeless forms. The interviewer administered the questionnaire. 'Current tobacco smoker' is defined as a person who currently smokes any tobacco product either daily or occasionally. 'Current smokeless tobacco user' is the one who currently uses any smokeless tobacco product either daily or occasionally. ${ }^{6}$ Throughout the survey, data quality and data management measures were applied. The prevalence rates of tobacco use (smoked and smokeless) exposure with respect to socio-demographic variables were calculated.

Further, a stepwise regression analysis was performed to determine the key socio-demographic factors associated with tobacco use. Significance was determined at $p<0.05$ and statistical analysis was performed in SPSS version 21 (SPSS Institute Inc). A $p$ value of less than 0.05 was considered statistically significant.

\section{Ethics}

A written informed voluntary consent was obtained by the study participants after ensuring anonymity and confidentiality. The Institute Ethical Committee (IEC) of Post Graduate Institute of Medical Education and Research, Chandigarh approved the study.

\section{RESULTS}

A total of 510 adults participated in the study (participation rate of $100 \%$ ). By design, the study participants were selected equi proportionately to gender (equal males and females) and age group. Overall, the prevalence of 
current tobacco use was $11.5 \%$. The smoked form was more prevalent $(15.2 \%)$ as compared to smokeless $(7.8 \%)$ form. Sociodemographic distribution of participants is shown in Table 1.

The factors associated with smoked and smokeless tobacco use are shown in Table 2. Higher prevalence of smoked tobacco users was found among males, middle to elderly age group, urban locality, those with no formal schooling and non- government employed category. Similarly, the prevalence of smokeless tobacco users was higher among the males, 25-44 year age group, urban locality, middle education, and non-government employee occupation category.

Table 2 shows that as the age increased the odds ratio for smoked tobacco users also increased with 4 times more in age 45 and above category (OR 4.9, 95\% CI 1.4, 16.8) as compared to the younger age group. In addition, an antagonistic relationship between education and use of smoked tobacco was observed as the odds ratio decreased with increasing level of education.(OR 0.83-0.13, C.I. 0.23-2.97,0.02-0.74)

For smokeless tobacco users, in reference to younger population, the adult population had 3 times higher odds (OR 3.2, and 95\% CI 0.8, 11.9) of smokeless tobacco use. The ORs of smokeless tobacco users decreased with increasing age and education level. No significant relation of tobacco use with gender and locality was reported in the study.

\section{DISCUSSION}

The statewide representative survey showed an overall low prevalence of tobacco use among the population as compared to other states of the country. One of the probable reasons for the low prevalence of tobacco use among the adult population is the impact of various measures undertaken by the government of Punjab in effectively enforcing the legislation. Another reason could be due to the prohibition of smoking in the Sikh religion (dominant religion of Punjab) prohibits the consumption of tobacco. ${ }^{13}$

In the present study, the overall tobacco use was reported to be $11.5 \% ; 23.1 \%$ among males and none among females. The smoked form contributed $15.2 \%$ of the male population while smokeless contributed $7.8 \%$. The hand-rolled cigarettes (bidis) contributed 64.1\% to the total tobacco usage. Tobacco users were $15.3 \%$ in urban population and $10 \%$ in the rural population. The maximum number of tobacco users were seen in the age group of 25-44 years. The middle education and non-government employee occupation had the most

Table 1: Sociodemographic distribution of current tobacco users aged 15 years and above in Punjab, India

\begin{tabular}{|c|c|c|c|c|c|c|}
\hline \multirow{2}{*}{$\begin{array}{l}\text { Demographic } \\
\text { characteristics }\end{array}$} & \multicolumn{4}{|c|}{ Current smokers $n(\%)$} & \multirow{2}{*}{$\begin{array}{l}\text { Current smokeless } \\
\text { tobacco users n (\%) }\end{array}$} & \multirow{2}{*}{$\begin{array}{l}\text { Current tobacco } \\
\text { users } n(\%)\end{array}$} \\
\hline & Total $(N=510)$ & Manufactured & Hand rolled & Total & & \\
\hline \multicolumn{7}{|l|}{ Gender } \\
\hline Male & $255(50)$ & $14(35.8)$ & $25(64.1)$ & $39(15.2)$ & $20(7.8)$ & $59(23.1)$ \\
\hline Female & $255(50)$ & $0(0)$ & $0(0)$ & $0(0)$ & $0(0)$ & $0(0)$ \\
\hline \multicolumn{7}{|l|}{ Age(years) } \\
\hline $15-24$ & $139(27.2)$ & $2(50)$ & $2(50)$ & $4(2.8)$ & $3(2.1)$ & $7(5.0)$ \\
\hline $25-44$ & $258(50.5)$ & $9(47.3)$ & $10(52.6)$ & $19(7.3)$ & $15(5.8)$ & $34(13.1)$ \\
\hline 45 and above & $113(22.1)$ & $3(18.7)$ & $13(81.2)$ & $16(14.1)$ & $2(1.7)$ & $18(15.9)$ \\
\hline \multicolumn{7}{|l|}{ Residence } \\
\hline Urban & $150(29.4)$ & $3(17.6)$ & $14(82.3)$ & $17(11.3)$ & $6(4)$ & $23(15.3)$ \\
\hline Rural & $360(70.5)$ & $11(50)$ & $11(50)$ & $22(6.1)$ & $14(3.8)$ & $36(10)$ \\
\hline \multicolumn{7}{|l|}{ Education } \\
\hline No formal schooling & $72(14.1)$ & $1(10)$ & $9(90)$ & $10(13.8)$ & $3(4.1)$ & $13(18.0)$ \\
\hline Primary & $46(9.0)$ & $2(33.3)$ & $4(66.6)$ & $6(13.0)$ & $3(6.5)$ & $9(19.5)$ \\
\hline Middle & $77(15.0)$ & $2(22.2)$ & $7(77.7)$ & $9(11.6)$ & $8(10.3)$ & $17(22.0)$ \\
\hline High & $144(28.2)$ & $4(57.1)$ & $3(42.8)$ & $7(4.8)$ & $6(4.1)$ & $13(9.0)$ \\
\hline Senior secondary & $84(16.4)$ & $4(80)$ & $1(20)$ & $5(5.9)$ & $0(0)$ & $5(5.9)$ \\
\hline $\begin{array}{l}\text { Graduate/ } \\
\text { Postgraduate }\end{array}$ & $87(17.0)$ & $1(50)$ & $1(50)$ & $2(2.2)$ & $0(0)$ & $2(2.2)$ \\
\hline \multicolumn{7}{|l|}{ Occupation } \\
\hline Student & $62(12.1)$ & $0(0)$ & $0(0)$ & $0(0)$ & $0(0)$ & $0(0)$ \\
\hline $\begin{array}{l}\text { Government } \\
\text { employee }\end{array}$ & $34(6.6)$ & $1(100)$ & $0(0)$ & $1(2.9)$ & $0(0)$ & $1(2.9)$ \\
\hline $\begin{array}{l}\text { Non government } \\
\text { employee }\end{array}$ & $63(12.3)$ & $3(25)$ & $9(75)$ & $12(19.0)$ & $6(9.5)$ & $18(28.5)$ \\
\hline Self-employed & $156(30.5)$ & $8(38.0)$ & $13(61.9)$ & $21(13.4)$ & $14(8.9)$ & $35(22.4)$ \\
\hline $\begin{array}{l}\text { Retired and } \\
\text { unemployed }\end{array}$ & $48(9.4)$ & $2(40)$ & $3(60)$ & $5(10.4)$ & $0(0)$ & $5(10.4)$ \\
\hline Homemaker & $147(28.8)$ & $0(0)$ & $0(0)$ & $0(0)$ & $0(0)$ & $0(0)$ \\
\hline
\end{tabular}

Percentage in parentheses 
tobacco users. Tobacco use was found inversely related to the literacy levels.

Globally the prevalence of different forms of tobacco use varied across countries. Current tobacco use ranged from $27.2 \%$ in Thailand to $43.3 \%$ in Bangladesh. Exclusively smoking was more common in Indonesia (34.0\%) and Thailand (23.4\%) and less common in Bangladesh $(16.1 \%)$ and India (8.7\%). However, exclusive use of smokeless tobacco (SLT) was more common in Bangladesh $(20.3 \%)$ and India $(20.6 \%)$ and less common in Indonesia $(0.9 \%)$ and Thailand (3.5\%). In general, the different forms of tobacco use increased among males and with increasing age; and decreased with higher education and wealth. ${ }^{14}$

Global Adult Tobacco Survey (GATS) India 20092010 reported current tobacco use in any form as $34.6 \%$ in adults; $47.9 \%$ of males and $20.3 \%$ of females. The proportion of smokers was $14.0 \%$ whereas those consuming smokeless tobacco products were $25.9 \% .{ }^{1}$ GATS report 2009-2010 in Punjab stated that current tobacco users in any form were $11.7 \%$, among which $21.6 \%$ were males and $0.5 \%$ females. Around $6.9 \%$ of adults; $(12.7 \%$ of males and $0.4 \%$ of females) indulged in smoking, whereas, $6.5 \%$ were users of smokeless tobacco products $\left(12.2 \%\right.$ of males and $0.2 \%$ of females). ${ }^{1}$ A statewide study by Thakur et al. also reported that overall current tobacco smoking was more prevalent than smokeless tobacco consumption with an overall prevalence of tobacco use (both smoked and smokeless) as $11.3 \% .{ }^{15}$ The findings of the current study are quite similar to the above-mentioned survey results as it also reports more smoked tobacco users as compared to smokeless tobacco users.

In general, tobacco use increased with increasing age, which could be explained by the increasing initiation of tobacco at a younger age and reduced quitting so that by the time a particular age is reached, most users adopt this habit with the development of nicotine dependence. The results of the current study corroborate with findings of Singh et al., who also reported that the odds of using tobacco significantly increased with an increase in age. ${ }^{16}$ Another study by Rani et al. reported that the observed increase in tobacco use prevalence could be partly imputed to under-reporting in the younger age groups and partly to an actual increase in the prevalence of tobacco consumption with age up to mid-50s. ${ }^{17}$

Bidi smoking formed a major proportion of tobacco smoking in the current study because bidi is relatively a cheaper and easily affordable product. Studies by Chadda et al. and Sinha et al. also reported that bidis are comparatively low priced making their purchase more economical thereby increasing the affordability and access to the users. ${ }^{18,19}$ Low pricing could also be attributed to lower taxation slab applicable to them. ${ }^{19}$

Table 2: Factors associated with current smoked and smokeless tobacco use among adults aged 15 years and above in Punjab, India

\begin{tabular}{|c|c|c|c|c|c|}
\hline Demographic characteristics & $\begin{array}{l}\text { Total } \\
N(\%)\end{array}$ & $\begin{array}{l}\text { Current } \\
\text { smokers N (\%) }\end{array}$ & $\begin{array}{l}\text { Odds ratio } \\
\text { (95\% C.I.) }\end{array}$ & $\begin{array}{l}\text { Current smokeless } \\
\text { tobacco users (\%) }\end{array}$ & $\begin{array}{l}\text { Odds ratio } \\
\text { (95\% C.I.) }\end{array}$ \\
\hline \multicolumn{6}{|l|}{ Gender } \\
\hline Male & $255(50)$ & $39(15.2)$ & Reference & $20(7.8)$ & Reference \\
\hline Female & $255(50)$ & $0(0)$ & $0.0(0.0)$ & $0(0)$ & $0.0(0.0)$ \\
\hline \multicolumn{6}{|l|}{ Age (years) } \\
\hline $15-24$ & $139(27.2)$ & $4(2.8)$ & Reference & $3(2.1)$ & Reference \\
\hline $25-44$ & $258(50.5)$ & $19(7.3)$ & $3.47(1.0-11.0)$ & $15(5.8)$ & $3.2(0.85-11.9)$ \\
\hline 45 and above & $113(22.1)$ & $16(14.1)$ & $4.98(1.4-16.87)$ & $2(1.7)$ & $0.4(0.07-3.16)$ \\
\hline \multicolumn{6}{|l|}{ Residence } \\
\hline Urban & $150(29.4)$ & $17(11.3)$ & Reference & $6(4)$ & Reference \\
\hline Rural & $360(70.5)$ & $22(6.1)$ & $0.45(0.21-0.97)$ & $14(3.8)$ & $0.94(0.32-2.73)$ \\
\hline \multicolumn{6}{|l|}{ Education } \\
\hline No formal schooling & $72(14.1)$ & $10(13.8)$ & Reference & $3(4.1)$ & Reference \\
\hline Primary & $46(9.0)$ & $6(13.0)$ & $0.83(0.23-2.97)$ & $3(6.5)$ & $1.25(0.21-7.28)$ \\
\hline Middle & $77(15.0)$ & $9(11.6)$ & $0.59(0.19-1.80)$ & $8(10.3)$ & $1.69(0.39-7.36)$ \\
\hline High & $144(28.2)$ & $7(4.8)$ & $0.27(0.87-0.85)$ & $6(4.1)$ & $0.82(0.18-3.69)$ \\
\hline Senior secondary & $84(16.4)$ & $5(5.9)$ & $0.53(0.14-1.98)$ & $0(0)$ & $0.0(0.0)$ \\
\hline Graduate/Postgraduate & $87(17.0)$ & $2(2.2)$ & $0.13(0.02-0.74)$ & $0(0)$ & $0.0(0.0)$ \\
\hline \multicolumn{6}{|l|}{ Occupation } \\
\hline Student & $62(12.1)$ & $0(0)$ & $0.0(0.0)$ & $0(0)$ & $0.0(0.0)$ \\
\hline Government employee & $34(6.6)$ & $1(2.9)$ & Reference & $0(0)$ & $0.0(0.0)$ \\
\hline Non government employee & $63(12.3)$ & $12(19.0)$ & $4.82(0.52-44.5)$ & $6(9.5)$ & Reference \\
\hline Self-employed & $156(30.5)$ & $21(13.4)$ & $2.94(0.34-25.24)$ & $14(8.9)$ & $1.36(0.47-3.87)$ \\
\hline Retired and unemployed & $48(9.4)$ & $5(10.4)$ & $3.23(0.31-32.8)$ & $0(0)$ & $0.0(0.0)$ \\
\hline Homemaker & $147(28.8)$ & $0(0)$ & $0.0(0.0)$ & $0(0)$ & $0.0(0.0)$ \\
\hline
\end{tabular}

${ }^{*}$ Percentage in parentheses 
The variations related to tobacco use patterns across different states of the country have been documented where smokeless tobacco use is more prevalent in the Central, Eastern and North-eastern states. ${ }^{19}$ The migration of people of lower socioeconomic groups from central India towards northern (Punjab) region in search of better work opportunities might bring with them their smokeless tobacco usage habits. Sorensen et al. and Bhawna too reported that tobacco use was rampant among the disadvantaged socioeconomic groups and found tobacco use to be inversely related to educational levels. ${ }^{13,20}$ The $25-44$ years age group and nongovernment employee occupation category had maximum smokeless tobacco users in the study which may be because this age group also acquires financial independence and they take their decisions independently to purchase tobacco products. The increasing educational level had an overall protective effect for both forms of tobacco use is defined as a person awareness about the ill effects of smoking and tobacco use increases, which deter them to use tobacco products.

The recently released factsheet of GATS-2 (2016-2017) for Punjab has reported an increase in tobacco use from $12 \%$ to $13.4 \%$ which calls for multipronged efforts by the state for tobacco control. ${ }^{21}$

\section{Strengths and Limitations}

The present study can be regarded as the first state-wide study following the standardized methodology of Global Adult Tobacco Survey 2009-2010. The predictors of tobacco use were comprehensively assessed and the nonresponse rate was nil. The Strengthening the Reporting of Observational Studies in Epidemiology (STROBE) guidelines where strictly adhered to while reporting the study results. The underreporting due to social desirability bias (i.e. fear of not following the general social norms of no-tobacco-use) might be an inherent limitation of the study . Also, temporal relationship between various variables with tobacco consumption is not reflected in the study findings. The institutionalised population was not taken for survey, which may under or over estimate the prevalence. Due to limited time period for the study, it could not be extended to more than three districts. The present results, however, can provide a basis for comparison of the study variables across the districts which can be explored in further studies.

\section{CONCLUSION}

Despite low prevalence of tobacco use in Punjab, the majority of existing tobacco users belong to low socioeconomic strata which indicates differences in norms and practices regarding tobacco use among different socioeconomic classes. To reduce the overall tobacco consumption, the tobacco control measures should be focused on low socio-economic groups. Multi-stakeholder engagement is important for sustaining tobacco control efforts and better implementation of National Tobacco Control Programme. ${ }^{22}$ The future strategy should focus on mix of behavioural and legislative intervention including high compliance to smoke free law. ${ }^{23}$ Future qualitative research is warranted to explore the interlinked psychosocial issues for initiation of tobacco use among vulnerable groups.

\section{ACKNOWLEDGMENT}

Authors want to thank State Tobacco Control Cell, Punjab for their technical support in the current study.

\section{REFERENCES}

1. Government of India. Ministry of Health \& Family Welfare, Global Adult Tobacco Survey, India.2009-2010.

2. Drope J, Schluger N, Cahn Z, Drope J, Hamill S, Islami F, et al. The Tobacco Atlas. Atlanta: American Cancer Society and Vital Strategies. 2018.

3. Atlanta, Georgia, 30303, USA: Published by the American Cancer Society; 2015.

4. Forouzanfar MH, Alexander L, Anderson HR, Bachman VF, Biryukov S, Brauer M, et al. Global, regional, and national comparative risk assessment of 79 behavioural, environmental and occupational, and metabolic risks or clusters of risks in 188 countries, 1990-2013: a systematic analysis for the Global Burden of Disease Study 2013. Lancet.2015;386(10010):2287-2323.

5. World Health Organization. WHO report on the global tobacco epidemic, 2013 enforcing bans on tobacco advertising, promotion and sponsorship [Internet]. Geneva: World Health Organization;2013.

6. U.S. Department of Health and Human Services. The Health Consequences of Smoking-50 Years of Progress: A Report of the Surgeon General. Atlanta: U.S. Department of Health and Human Services, Centers for Disease Control and Prevention, National Center for Chronic Disease Prevention and Health Promotion, Office on Smoking and Health, 2014.

7. World Health Organization. WHO Framework Convention on Tobacco Control, Geneva.2003.

8. Government of India. The Cigarettes and Other Tobacco Products (Prohibition of Advertisement and Regulation of Trade and Commerce, Production, Supply and Distribution) Act, and rules framed there under. 2003.

9. National tobacco control programme, report by Tobacco control cell Punjab.

10. Government of India. Ministry of Home Affairs. Directorate of Census Operations, Punjab.

11. Binson D, Catania JA. Random selection in a national telephone survey: a comparison of the Kish, next-birthday, and last-birthday methods. Journal of Official Statistics. 2000 Mar 1;16(1):53.

12. Centres for Disease Control and Prevention. World Health Organisation. Tobacco Questions for Surveys, 2nd edition; 2011.

13. Bhawna G. Burden of smoked and smokeless tobacco consumption in India-results from the global adult tobacco survey India (GATS-India)-2009-2010. Asian Pacific Journal of Cancer Prevention. 2013;14(5):3323-9. 
14. Palipudi K, Rizwan SA, Sinha DN, Andes LJ, Amarchand R, Krishnan A, et al. Prevalence and sociodemographic determinants of tobacco use in four countries of the World Health Organization: South-East Asia region: findings from the Global Adult Tobacco Survey. Indian journal of cancer. 2014 Dec 1;51(5):24.

15. Thakur JS, Jeet G, Pal A, Singh S, Singh A, Deepti SS, et al. Profile of risk factors for non-communicable diseases in Punjab, Northern India: Results of a state-wide STEPS survey. PLoS One. 2016 Jul 7;11(7):e0157705.

16. Singh A, Ladusingh L. Prevalence and determinants of tobacco use in India: Evidence from recent global adult tobacco survey data. PloS one. 2014 Dec 4;9(12):e114073.

17. Rani M, Bonu S, Jha P, Nguyen SN, Jamjoum L. Tobacco use in India: prevalence and predictors of smoking and chewing in a national cross sectional household survey. Tobacco control. 2003 Dec 1;12(4):e4.

18. Chadda RK, Sengupta SN. Tobacco use by Indian adolescents. Tobacco induced diseases. 2002 Jun;1(2):111.
19. Sinha DN, Palipudi KM, Rolle I, Asma S, Rinchen S. Tobacco use among youth and adults in member countries of SouthEast Asia region: Review of findings from surveys under the global tobacco surveillance system. Indian J Public Health 2011;55:169-176.

20. Sorensen G, Gupta PC, Pednekar MS. Social disparities in tobacco use in Mumbai, India: the roles of occupation, education, and gender. American journal of public health. 2005 Jun;95(6):1003-1008.

21. Government of India. Ministry of Health \& Family Welfare, Global Adult Tobacco Survey,India. 2016-2017.

22. Ravindra K, Tripathy JP, Tripathy NK. Dynamics of multistakeholder engagement and its role in achieving high compliance of a tobacco control programme. World Development Perspectives. 2016 Sep 1;3:7-11.

23. Goel S, Ravindra K, Singh RJ, Sharma D. Effective smoke-free policies in achieving a high level of compliance with smokefree law: experiences from a district of North India. Tobacco control. 2014 Jul 1;23(4):291-294. 